\title{
Synthesis of LN/Si Nanostructures Layer by LayerBased on Mach-Zehnder Modulator using Pulsed Laser Deposition
}

\section{Luma Z. Mohammed}

University of Technology-Iraq, Baghdad, Iraq

Makram A Fakhri ( $\square$ mokaram_76@yahoo.com )

University of Technology, Baghdad https://orcid.org/0000-0001-9010-6121

\section{A. K. Abass}

University of Technology-Iraq

Evan T. Salim

University of Technology

\section{Original Research}

Keywords: optical modulator, LN/SiO/Si, physical properties, PLD

Posted Date: February 18th, 2021

DOI: https://doi.org/10.21203/rs.3.rs-206042/v1

License: @ (i) This work is licensed under a Creative Commons Attribution 4.0 International License. Read Full License 


\title{
Synthesis of LN/Si Nanostructures Layer by LayerBased on Mach-Zehnder Modulator using Pulsed Laser Deposition
}

\author{
Luma Z. Mohammed ${ }^{1}$, Makram A. Fakhri ${ }^{1, *}$, A. K. Abass ${ }^{1}$, Evan T. Salim ${ }^{2, *}$ \\ ${ }^{1}$ Laser and Optoelectronic department, University of Technology, 10066 Baghdad, Iraq. \\ ${ }^{2}$ Applied science department, University of Technology, 10066 Baghdad, Iraq
}

\begin{abstract}
A Mach-Zehnder electro-optic modulator (EOM) was fabricated employing pulsed laser deposition (PLD) method. Lithium Niobate (LN) was bonded to silicon nanocrystal substrate such that a waveguide combined structures were obtained. The over-all Properties of prepared device were investigated. The formation of $\mathrm{LN}$ was ensured by the $\mathrm{x}$-ray diffraction results were the formation of $\Delta$ phase was confirmed by the diffraction of x-rays from the (012) and (302) diffraction plans. The AFM results reflect the formation of highly uniform nanostructured with maximum roughness of about $12.9 \mathrm{~nm}$. The constructed device shows that the recent improvements in hybrid MZ modulators using pulse laser deposition PLD and different electro-optic material have shown low loss and wide modulation bandwidth.
\end{abstract}

Keywords: optical modulator; $\mathrm{LN} / \mathrm{SiO} / \mathrm{Si}$, physical properties, PLD

\section{Introduction}

High performance electroptic modulation based on lithium Niobate LN EOMs had enormous studies underlies many important applications ranging from optical communication, microwave photonics, computing, frequency be commercially available due to their engaging features, low insertion loss, large modulation bandwidth, low drive voltage, enhanced linearity, consolidated foot-print and low effect of dispersion [1, 2]. However, the conventional $\mathrm{LiNbO}_{3}$ modulators have a bulky size and modulation efficiency is low (V $\pi . \mathrm{L}>10 \mathrm{~V} . \mathrm{cm} \mathrm{[3]}$, high manufacturing cost, the electric drive power that desired is high $[4,5]$.

LN represent a considerable ferroelectric material of high interest in the field of telecommunications and optics because of its high electro-optic effect depended on Pockels

*For correspondence; Tel. + (964) 7702793869, E-mail: mokaram_76@yahoo.com, 140017@uotechnology.edu.iq

*For correspondence; Tel. + (964) 7715752087, E-mail: evan tarq@yahoo.com , 100354@uotechnology.edu.iq 
effect and non-linear coefficients [6-8]. This material has many application as wavelength converter, optoelectronic modulator, waveguide [3], Q-switches crystal for lasers application, and in quantum optics devices [9]. The most important electro-optical modulator is the MachZehnder modulator (MZM) that used in a wide variety of applications within optics and optical communications [10].

When we talk about LN electro-optic modulators several works could be found along the last two decades. Almost all of them show an active potential underway to adjust the design and fabrication of $\mathrm{MZ}$ modulators to be convenient with fabrication of the modern integrated photonics technology, this include hetero-structure integration with nano-silicon and nonaphotonics components $[11,12]$.

In this work, hybrid MZ modulators have been fabricated and investigated starting from physical properties of constructed thin film towards MZ modulators performance.

\section{Methodology}

\subsection{Experimental work}

The hybrid LN/silicon Mach-Zehnder modulator structure on silicon substrate was concerned, the reparation process was accomplished by the PLD technique using tattoo removal Q switching Nd: YAG laser at wavelength $1064 \mathrm{~nm}$. Fig. 1a shows the schematic diagram of the experimental setup. In our design, a buffer layer of silicon oxide $\left(\mathrm{SiO}_{2}\right)$ with the optimum thickness on silicon nanostructure was deposited as an Optical wave Guide structure, another layer of SiO2 deposited on the Silicone layer, finally, a nano-then layer of the lithium niobate nanostructure X-cut was deposited over the three aforementioned layers as present in fig 1 -b

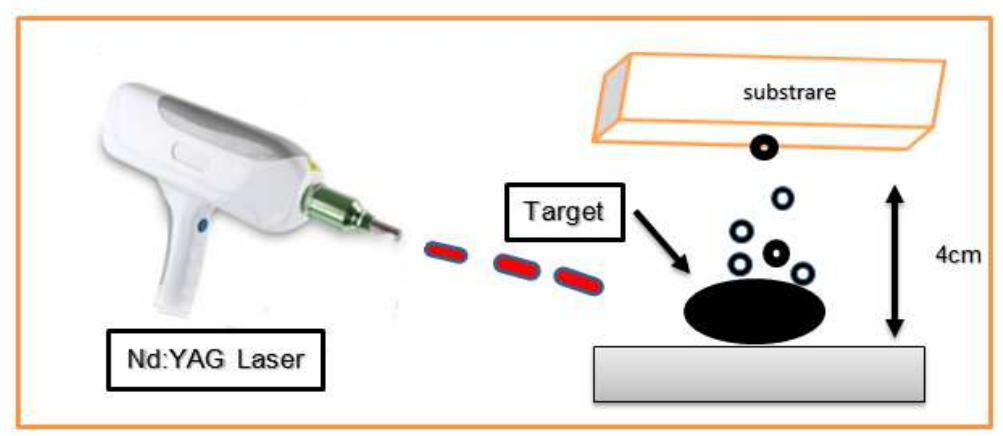



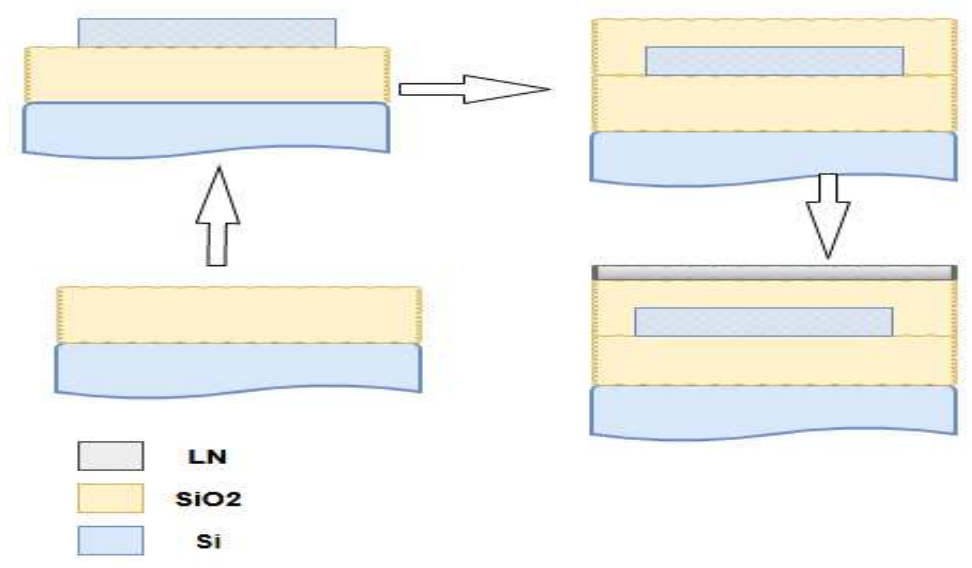

Figure (1) (a) PLD deposition process. (b) Cross-section of the MZM with silicon waveguide, $\mathrm{SiO}_{2}$ layer between the LN features and the silicon substrate.

The as-deposited structure properties of the prepared MZM were investigated using (Shimadzu 6000) X-ray diffraction system. A (Jobin Yvon model HR $800 \mathrm{UV}$ ) system has been used to investigate the photo-luminescence employing a He-Cd laser $352 \mathrm{~nm}$. The film thickness was measured using the scanning optical reflectometer (Model: Filmetrics F20, USA). A UV-vis spectrophotometer from Shimadzu UV-vis 1800 Japan was used to measure the optical properties. The optical constant such as band energy, the index of refraction, and the dielectric properties. The SEM was used to observe the surface morphology while AFM was used to determine the RMS of MZ modulators surface.

\subsection{Theory}

$\mathrm{E}=\mathrm{hv}$ is the incident photon energy if we write it as a function of the wavelength $(\lambda)$ will give $[13,14]$

$$
\operatorname{Eg}(e V)=\frac{1.24}{\lambda(u m)}
$$

According to Tauc equation, the energy dependence of absorption coefficient $(\alpha)$ close to the band edge could be described by .[ ]

$$
(\alpha h v)=B(h v-E g)^{r}
$$

Where, $(\alpha)=$ absorption coefficient,$(h)=$ Planck's constant,$(v)=$ speed of light, $\mathrm{B}=$ constant that proportion inversely surface roughness. $(r)=$ coefficient that dependent on material type. 
The gap energy can obtained from the intercepting of the straight line between $(\alpha h v)^{1 / \mathrm{r}}$ as a function of $(h v)$, the extrapolating at $(\alpha h v)^{1 / \mathrm{r}}=0 \mathrm{Eq}$. (3) is used to estimate the energy gap

$$
\alpha=2.303\left(\frac{A}{t}\right)
$$

Where $(t)$ and $(A)$ are the thickness and absorption photonic nano-films. The value of the absorption coefficient $(\alpha)$ as a function of extinction coefficient $(K)$ could be obtained from the following Eq. (4)

$$
K=\frac{\alpha \lambda}{4 \pi}
$$

The real and imaginary parts of dielectric constant, refractive index, and the optical conductivity can be calculated from Eq. (5):

$$
n=\left\{\frac{4 R}{R-1}-K^{2}\right\} 1 / 2-\frac{R+1}{R-1}
$$

$(R)=$ reflectance where $(R=1-T-R)$

$(K)=$ extinction coefficient given in eq. (6): [15]

$$
n=n_{s}\left(\frac{1+\sqrt{R}}{1-\sqrt{R}}\right)^{0.5}
$$

$n_{s}=$ refractive index

In this work the used substrate refractive index is (1.5).

The Dielectric constants could be obtained from Eq. (7)

$$
\varepsilon=\varepsilon_{1}-i \varepsilon_{2}
$$

Where, $\varepsilon r=n^{2}-K^{2}, " \varepsilon_{i}=2 n K$, Finally, the optical conductivity can be given through Eq. (8)

$$
\delta=\frac{\alpha n c}{4 \pi}
$$

$\mathrm{C}=$ light speed in a vacuum.

Photoluminescence (PL) properties of the prepared samples were measured was measured by spectroscopy (Jobin- Yvon model HR 800 UV system, Kyoto, Japan) at room temperature using the He-Cd laser $(\mathrm{k}=352 \mathrm{~nm})$ [13]. 


\section{Results and discussion}

\subsection{Structural Properties}

The XRD spectra pattern of nanostructures of hybrid MZM optical modulator deposited on Si substrates deposited layer by layer silicon oxide, pure photonic silicon waveguide, and lithium niobate nanostructures are presented in fig. 2. All the peaks observed indicate that the nanostructures of all deposited successfully layers on the silicon substrate by grown by PLD technique, the XRD pattern shows multi diffraction peaks

where the diffraction peaks of the nano $\mathrm{LiNbO}_{3}$ films are appears of the polycrystalline at diffraction angles of $2 \theta=23.725^{\circ}, 32.825^{\circ}$, and $39.025^{\circ}$, for the corresponding to the (012), (104), and (006) planes respectively, the diffraction peaks of the pure photonic silicone nanofilms are appears also of the polycrystalline at diffraction angles of $2 \theta=24.925^{\circ}$, and $39.252^{\circ}$ for the correspond to (111), and (302) planes respectively, and the diffraction peaks of the nano silicone oxide films are appears of a single crystalline at a diffraction angle of $2 \theta$ $=44.375^{\circ}$.

The sizes of the crystallite for the deposited nanofilm are Grain size, the density of dislocation, and full width at high maximum for the prepared films were estimated

depended on XRD patterns calculated basis of the equation (9) of Scherrer as follows: [7, 16, $17]$.

$$
D=\frac{0.94 \lambda}{\beta \cos \theta}
$$

for the correspond to where the $\lambda$ value is the wavelength incident $X$-ray is equal $1.5406 \AA$, the value of the $\beta$ is the (full width at half maximum) of the peak, and finally, the $\theta$ is the diffraction angle at which the peak of a particular orientation occurs [8]. The size of the crystallite for the main peak of the nanofilms presented at peak of (012) is equal to $0.87 \mathrm{~nm}$. 


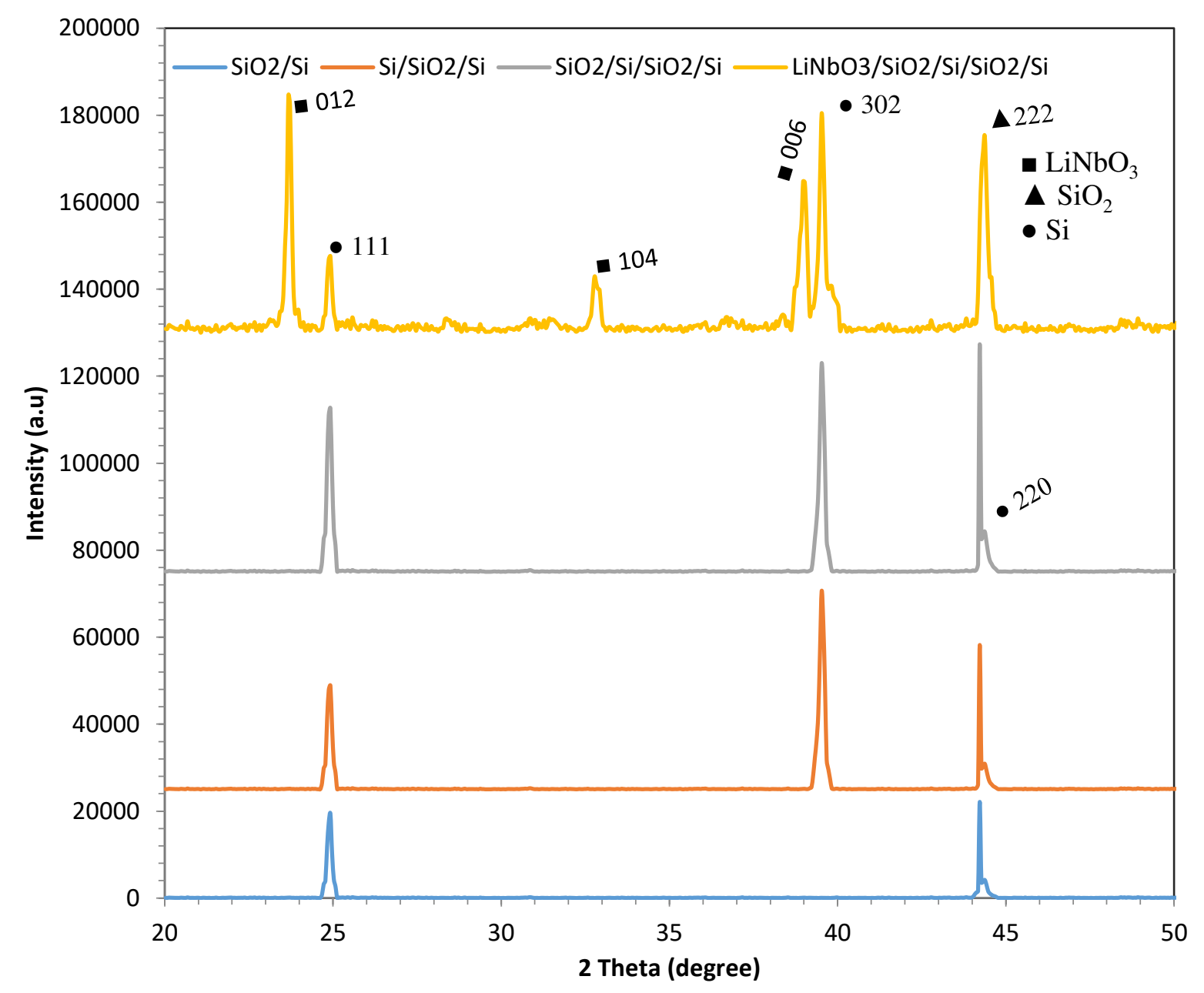

Fig. 2. XRD patterns of the MZM nanostructure on Si substrates

Also, the dislocation density $(\delta)$ and strain $(\varepsilon)$ of hybrid MZM nanostructures were determined using the following relations [7].

$$
\begin{gathered}
\delta=\frac{1}{D_{2}} \\
\boldsymbol{\varepsilon}=\frac{\beta}{4 \tan \theta}
\end{gathered}
$$

Small FWHM Large grain size, lower dislocation density, and strain values indicate better crystallization and a reduction of the defect in the hybrid MZ modulator as can be seen in figure 2 and table 1, The measured structural properties of $\mathrm{LiNbO}_{3}, \mathrm{SiO}_{2}, \mathrm{Si}$ with experimental value 
have better crystallization for the maximum peak of each material has appeared after the ultrasonic vibration process[16]

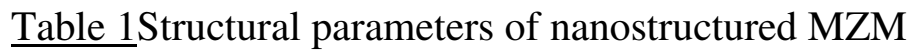

\begin{tabular}{|c|c|c|c|c|c|c|}
\hline layers & $\begin{array}{c}\text { Orientation } \\
h k l\end{array}$ & $\begin{array}{c}\text { Peak } \\
(2 \theta)\end{array}$ & $\beta(\mathrm{FWHM})$ & $\begin{array}{c}\text { Particle size } \\
\mathrm{D}(\mathrm{nm})\end{array}$ & $\begin{array}{c}\text { Dislocation density } \\
(\delta \text { lines } / \mathrm{m} 2)\end{array}$ & Strain $\varepsilon$ \\
\hline $\mathrm{LiNbO}_{3}$ & $(012)$ & 23.725 & 0.2 & 0.7396 & $1.828 * 10^{18}$ & 0.01048 \\
\hline $\mathrm{SiO}_{2}$ & $(302)$ & 39.525 & 0.26 & 0.8643 & $2.766^{*} 10^{18}$ & 0.0265 \\
\hline $\mathrm{Si}$ & $(222)$ & 44.375 & 0.17 & 0.6013 & $1.33 * 10^{18}$ & 0.01527 \\
\hline
\end{tabular}

\subsection{Morphological study}

\subsubsection{FESEM results}

The morphology of the prepared hybrid MZM layer by layer nanostructure on silicon substrates at the optimum temperature $\left(300^{\circ} \mathrm{C}\right)$ was tested via FESEM. Where it is a very important parameter for integrated-optic and optoelectronic applications. In this figure, we presented a picture for each layer, all presented images are equal in magnification size, also the deposition conditions were completely similar across all layers, it's clear that It appears that perfect distribution and the structure is smoother and more homogeneous for all presented layers, also we note the distribution of crystals are good balanced and the grain size is small and this enables us to use the deposited nanostructure layer by layer for optoelectronics and photonics devices as shown in Fig.3 (b) and Table (1). 

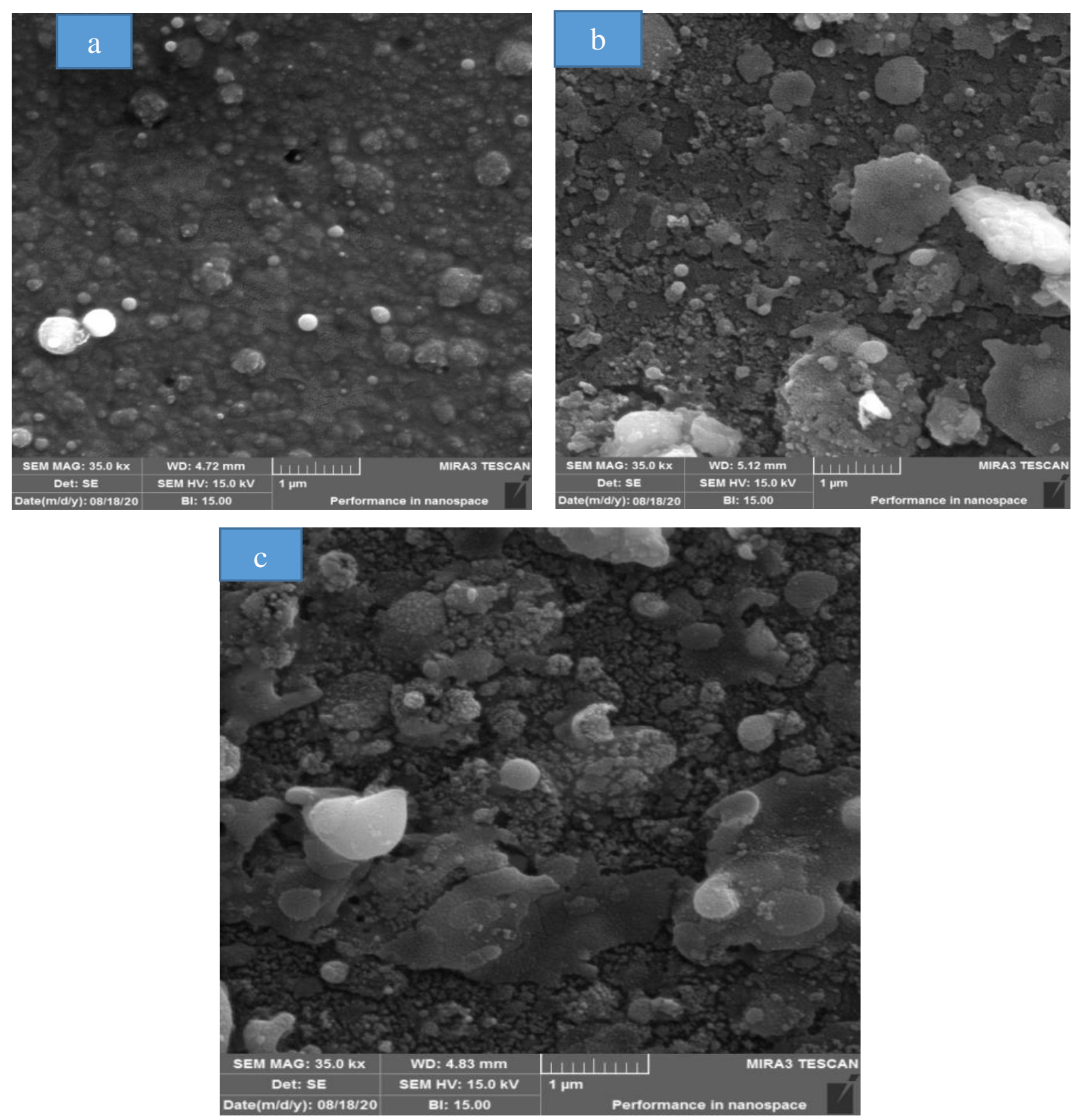

Fig. 3: Surface morphology of hybrid MZM nanostructures prepared at different layer a) $-\mathrm{SiO}_{2} / \mathrm{Si}_{\text {inbstrate, b) }}$ $\mathrm{Si}$ (waveguide) $/ \mathrm{SiO}_{2} / \mathrm{Si}$-substrate, and c) $\mathrm{LN} / \mathrm{SiO}_{2}$ ) Si(waveguide) $/ \mathrm{SiO}_{2} / \mathrm{Si}$ substrate

\subsubsection{AFM results}

The AFM images for hybrid MZ modulator surface films shows the RMS and grain size which are very remarkable parameters used to determine the materials used for integrated electro- optic applications. Fig. 4 a, b represents the dense surfaces and uniform compact. The uniformly 
distributed surface could be noted clearly with the $(2 \mathrm{~cm} \times 2 \mathrm{~cm})$ scanned area, a regular and smooth with individual vertical grains grown upwards the substrate. The average grains size is about $10.2 \mathrm{~nm}$ at the temperature of $300{ }^{\circ} \mathrm{C}$. According to surface roughness, a clear enhancement in terms of uniform distribution, the surface roughness of the surface and particle size was obtained.
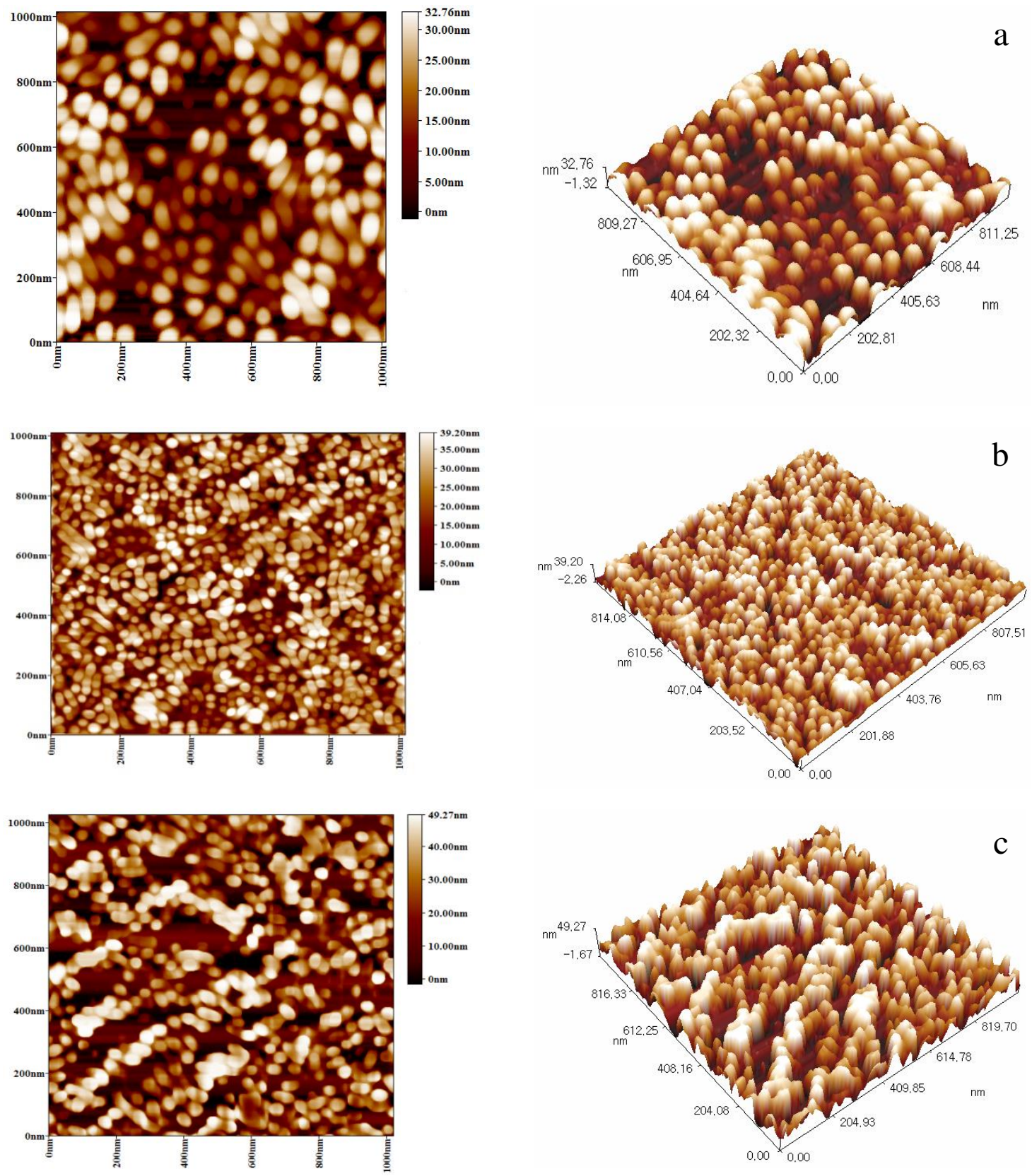

Fig (4) AFM images of nanostructured MZM a) $\left(\mathrm{SiO}_{2} / \mathrm{Si}\right)$, b) $\left(\mathrm{SiO}_{2} / \mathrm{Si}_{\mathrm{WG}} / \mathrm{SiO}_{2} / \mathrm{Si}\right)$, and c)

$\left(\mathrm{LiNbO}_{3} / \mathrm{SiO}_{2} / \mathrm{Si}_{\mathrm{WG}} / \mathrm{SiO}_{2} / \mathrm{Si}\right)$ 


\subsection{Optical properties}

Optical reflectance spectra of the MZ modulator bonded on silicon substrate could be shown in Fig. 5. The optical reflectance in the VIS-NIR regions increases as a function of wavelength. These obtained results may be related to the improved and successful formation and higher crystallization on the Silicon substrate and to the uniform inter-spaces of the nano road -like structure, which is also supported by the results of the XRD results.

The Kubelka-Munk function and Tauc plots has been used to estimate the energy band gap of the hybrid MZ modulator structure [8]. In this formula, $\mathrm{R}$ is the reflectance as given in Equation

$$
\mathrm{F}_{\mathrm{KM}}=\frac{1-R^{2}}{2 R}
$$

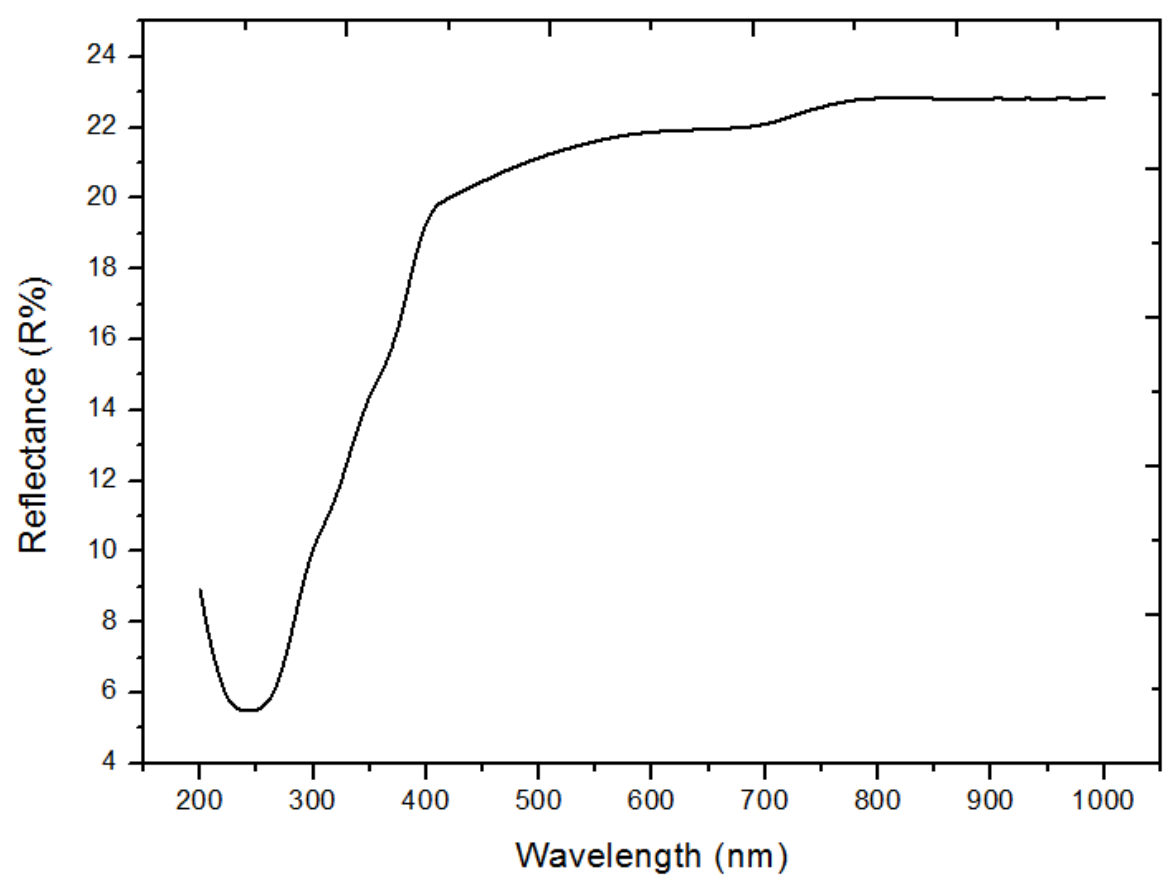

Fig. 5. Reflectance diagram of the MZM prepared on Si- substrates.

Fig.6 shows optical energy bandgap (Eg) of nanostructured of hybrid MZM, it value was deduced depended on extrapolation line of $(\alpha \mathrm{hv})^{2}$ as a function the incident wavelength energy (hv), using Tauc formula it has been evaluated [18, 19], Its value found to be about $\mathrm{Eg}=1.9 \mathrm{eV}$. 


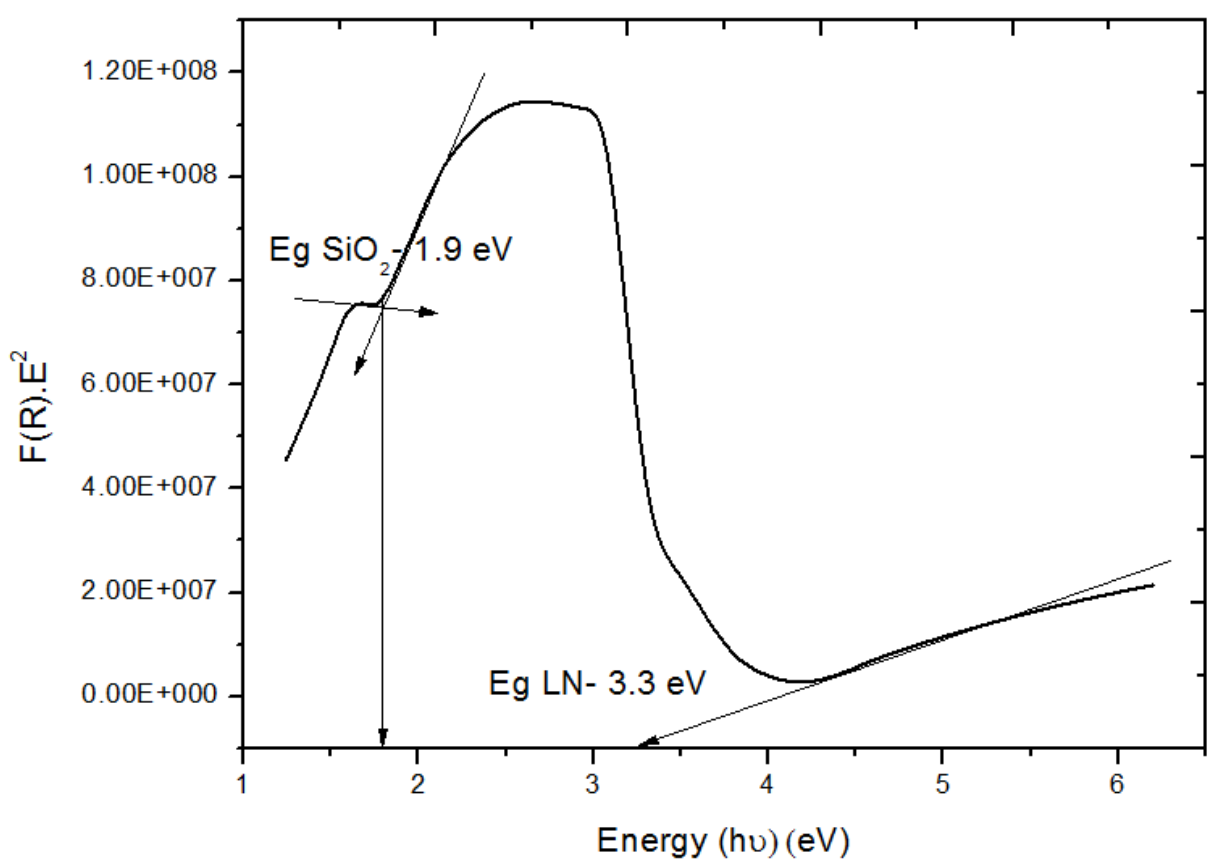

Fig.6 energy bandgap of MZM nanostructures

Eq.(10) has been used to estimate the absorption coefficient, which used later to found the the optical band gap $(\mathrm{Eg})[8,20]$,

$$
\boldsymbol{\alpha}=\frac{1}{D} \ln \frac{1}{T}
$$

$\mathrm{T}=$ transmittance, $\alpha=$ absorption coefficient, $\mathrm{D}=$ film thickness.

The index of refraction (n) has been estimated depended reflectance results and plotted Vs. wavelength with in the (200-800) nm optical range. An elevated refractive index value was observed in the visible region. It was estimated at $382 \mathrm{~nm}$ were the maximum absorption wavelength for $\mathrm{LN}$ nanostructure which reflect the higher refractive index of synthesized for the hybrid MZ modulator to be used as a good optical waveguide. 


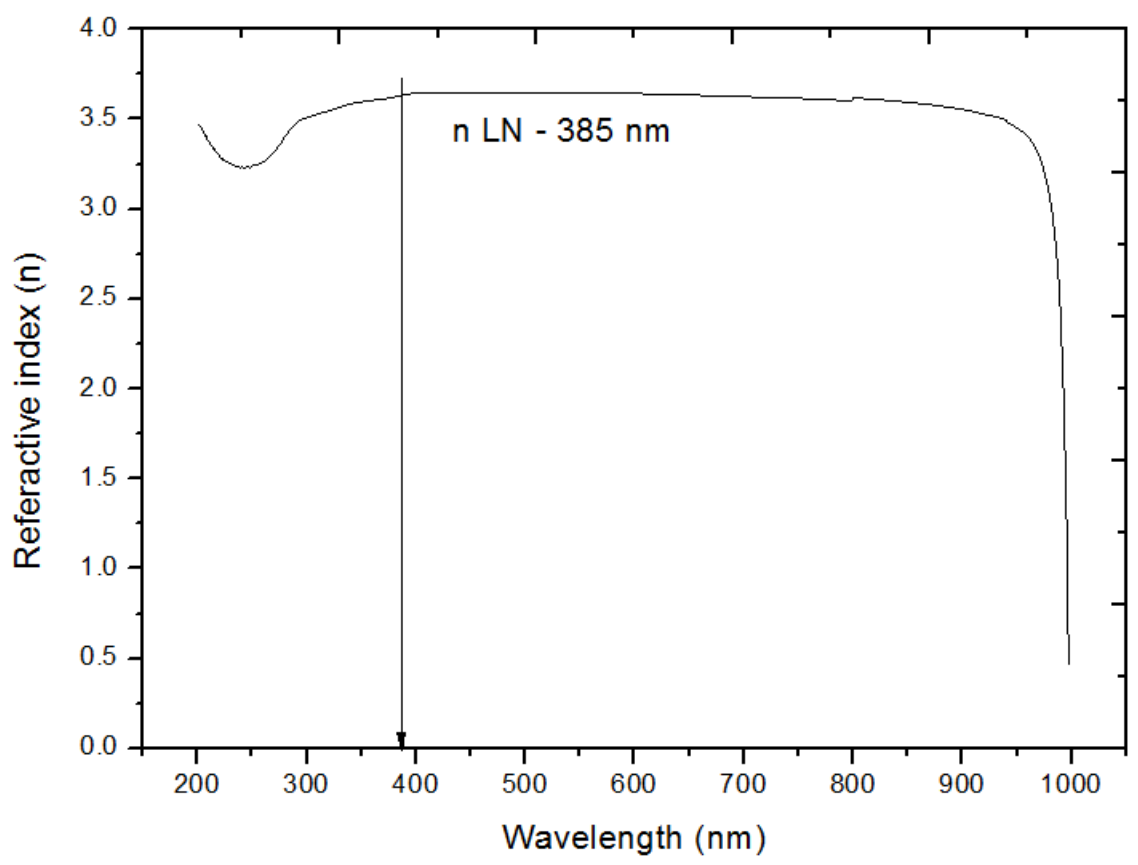

Fig.7 Refractive index of MZM nanostructure

The Photo lumnciense spectra of nanostructured hybrid MZ modulator grown on the silicon substrate is shown in fig(9). A clear and strong emissions peak in the visible region specifically at wavelength $376 \mathrm{~nm}(3.298 \mathrm{eV})$ could be observed. Photo-luminance spectra of hybrid MZ modulator ensure the high quality for the prepared material. The surface-to-volume ratio found to be low due to the low grains. The film with smaller grains has low non-radiated relaxation rates over the surface states which in turn leads to the increment of PL intensity. Furthermore, convergence of energy gaps measured in PL and UV-VIS ensure the formation of nanostructure that enhanced the photonic properties compared with the bulk material. 


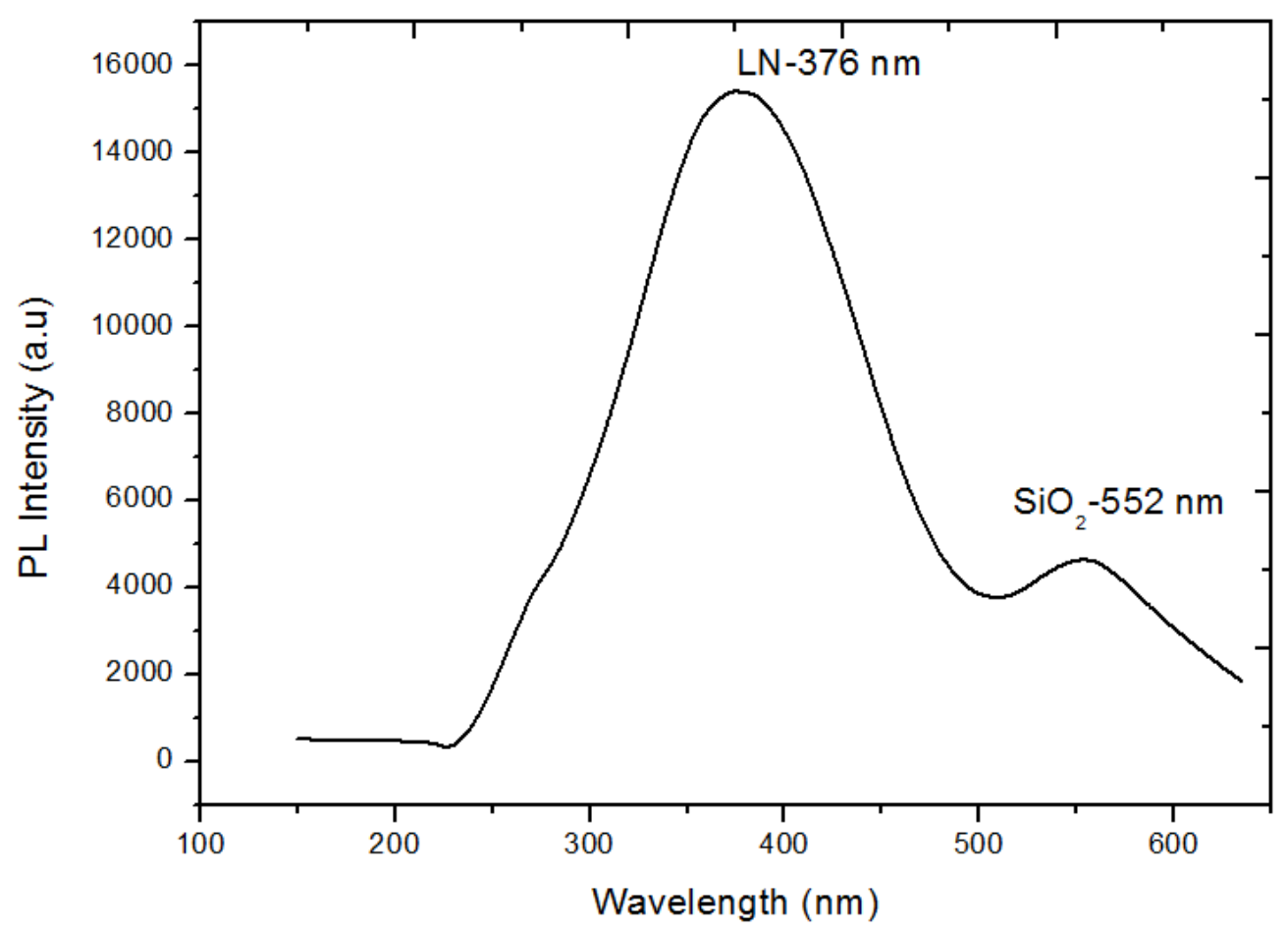

Fig (9) PL spectra diagram of hybrid MZM

\section{4-Conclusion}

A successful hybrid Si/LN MZ modulator could be constructed using PLD technique. It was found that the highest index is more appropriate for the optical waveguide. The PL spectra exhibit that the deposited MZ modulator has sufficient quality and the PL spectrum, it's clear that the LN where it works at the UV emission region films and its intensity is higher than the other peak of the $\mathrm{SiO}_{2}$ that works at the visible emission region.

\section{Refrence}

[1] M. Xu, W. Chen, M. He, X. Wen, Z. Ruan, J. Xu, L. Chen, L. Liu, S. Yu, X. Cai, Michelson interferometer modulator based on hybrid silicon and lithium niobate platform, APL Photonics, 4 (2019) 100802.

[2] D. Janner, D. Tulli, M. García-Granda, M. Belmonte, V. Pruneri, Micro-structured integrated electro-optic LiNbO3 modulators, Laser \& Photonics Reviews, 3 (2009) 301-313.

[3] P. Dong, L. Chen, Y.-k. Chen, High-speed low-voltage single-drive push-pull silicon MachZehnder modulators, Optics express, 20 (2012) 6163-6169. 
[4] C. Wang, M. Zhang, B. Stern, M. Lipson, M. Lončar, Nanophotonic lithium niobate electrooptic modulators, Optics express, 26 (2018) 1547-1555.

[5] I. Zareen, Development of optimum structure of a lithium niobate optical modulator considering dielectric loss, (2010).

[6] H. Han, B. Xiang, T. Lin, G. Chai, S. Ruan, Design and Optimization of Proton Exchanged Integrated Electro-Optic Modulators in X-Cut Lithium Niobate Thin Film, Crystals, 9 (2019) 549 .

[7] M.A. Fakhri, Y. Al-Douri, U. Hashim, E.T. Salim, XRD analysis and morphological studies of spin coated LiNbO3 nano photonic crystal prepared for optical waveguide application, in Advanced Materials Research, Trans Tech Publ, 2016, pp. 457-461.

[8] M.A. Fakhri, E.T. Salim, M. Wahid, A.W. Abdulwahhab, Z.T. Salim, U. Hashim, Heat treatment assisted-spin coating for $\mathrm{LiNbO} 3$ films preparation: their physical properties, Journal of Physics and Chemistry of Solids, 131 (2019) 180-188.

[9] M. He, M. Xu, Y. Ren, J. Jian, Z. Ruan, Y. Xu, S. Gao, S. Sun, X. Wen, L. Zhou, Highperformance hybrid silicon and lithium niobate Mach-Zehnder modulators for $100 \mathrm{Gbit}$ s- 1 and beyond, Nature Photonics, 13 (2019) 359-364.

[10] M. Zhang, K. Chen, W. Jin, K.S. Chiang, Electro-optic mode switch based on lithiumniobate Mach-Zehnder interferometer, Applied optics, 55 (2016) 4418-4422.

[11] N. Kikuchi, E. Yamada, Y. Shibata, H. Ishii, High-speed InP-based Mach-Zehnder modulator for advanced modulation formats, in: 2012 IEEE Compound Semiconductor Integrated Circuit Symposium (CSICS), IEEE, 2012, pp. 1-4.

[12] S. Jin, L. Xu, H. Zhang, Y. Li, LiNbO 3 thin-film modulators using silicon nitride surface ridge waveguides, IEEE Photonics Technology Letters, 28 (2015) 736-739.

[13] M.A. Fakhri, E.T. Salim, A.W. Abdulwahhab, U. Hashim, M.A. Munshid, Z.T. Salim, THE EFFECT OF ANNEALING TEMPERATURE ON OPTICAL AND PHOTOLUMINESCENCE PROPERTIES OF LiNbO3, Surface Review and Letters, 26 (2019) 1950068.

[14] M.A. Fakhri, M.H.A. Wahid, S.M. Kadhim, B.A. Badr, E.T. Salim, U. Hashim, Z.T. Salim, The structure and optical properties of Lithium Niobate grown on quartz for photonics application, in: EPJ Web of Conferences, EDP Sciences, 2017, pp. 01005. 
[15] M.A. Fakhri, E.T. Salim, A.W. Abdulwahhab, U. Hashim, Z.T. Salim, Optical properties of micro and nano LiNbO3 thin film prepared by spin coating, Optics \& Laser Technology, 103 (2018) 226-232.

[16] E.T. Salim, J.A. Saimon, M.K. Abood, M.A. Fakhri, Some physical properties of Nb2O5 thin films prepared using nobic acid based colloidal suspension at room temperature, Materials Research Express, 4 (2017) 106407.

[17] E.Y. Salih, Z. Abbas, S.H.H. Al Ali, M.Z. Hussein, Dielectric behaviour of Zn/Al-NO3 LDHs filled with polyvinyl chloride composite at low microwave frequencies, Advances in Materials Science and Engineering, 2014 (2014).

[18] E.Y. Salih, M.F.M. Sabri, M.Z. Hussein, K. Sulaiman, S.M. Said, B. Saifullah, M.B.A. Bashir, Structural, optical and electrical properties of ZnO/ZnAl 2 O 4 nanocomposites prepared via thermal reduction approach, Journal of Materials Science, 53 (2018) 581-590.

[19] E.Y. Salih, M.F.M. Sabri, S.T. Tan, K. Sulaiman, M.Z. Hussein, S.M. Said, C.C. Yap, Preparation and characterization of $\mathrm{ZnO} / \mathrm{ZnAl} 2 \mathrm{O}$ 4-mixed metal oxides for dye-sensitized photodetector using Zn/Al-layered double hydroxide as precursor, Journal of Nanoparticle Research, 21 (2019) 55.

[20] E.Y. Salih, M.F.M. Sabri, M.H. Eisa, K. Sulaiman, A. Ramizy, M.Z. Hussein, S.M. Said, Mesoporous $\mathrm{ZnO} / \mathrm{ZnAl} 2 \mathrm{O} 4$ mixed metal oxide-based $\mathrm{Zn} / \mathrm{Al}$ layered double hydroxide as an effective anode material for visible light photodetector, Materials Science in Semiconductor Processing, 121105370. 
Figures
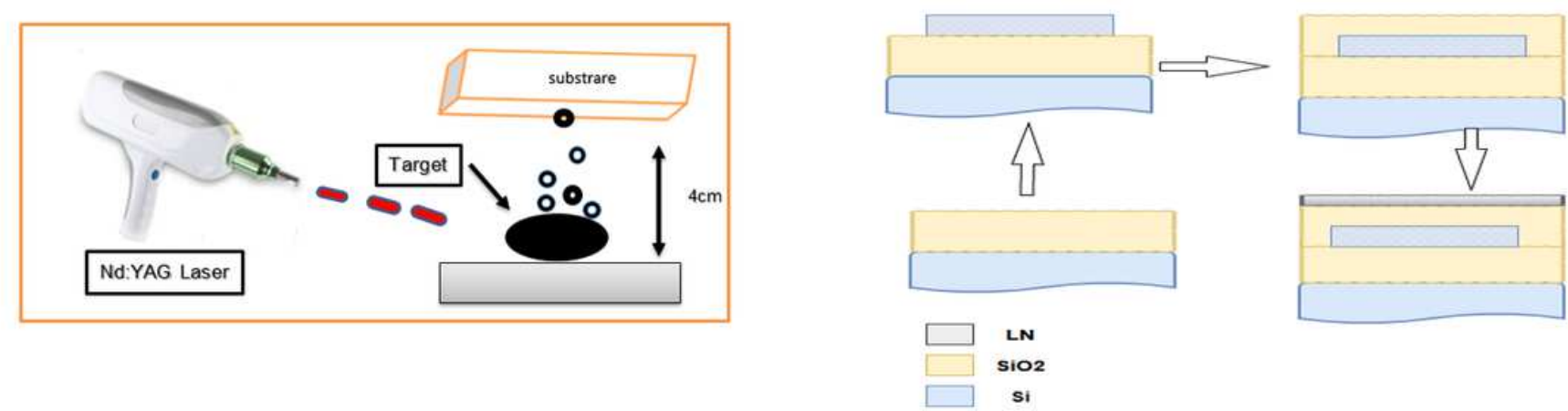

\section{Figure 1}

(a) PLD deposition process. (b) Cross-section of the MZM with silicon waveguide, SiO2 layer between the LN features and the silicon substrate. 


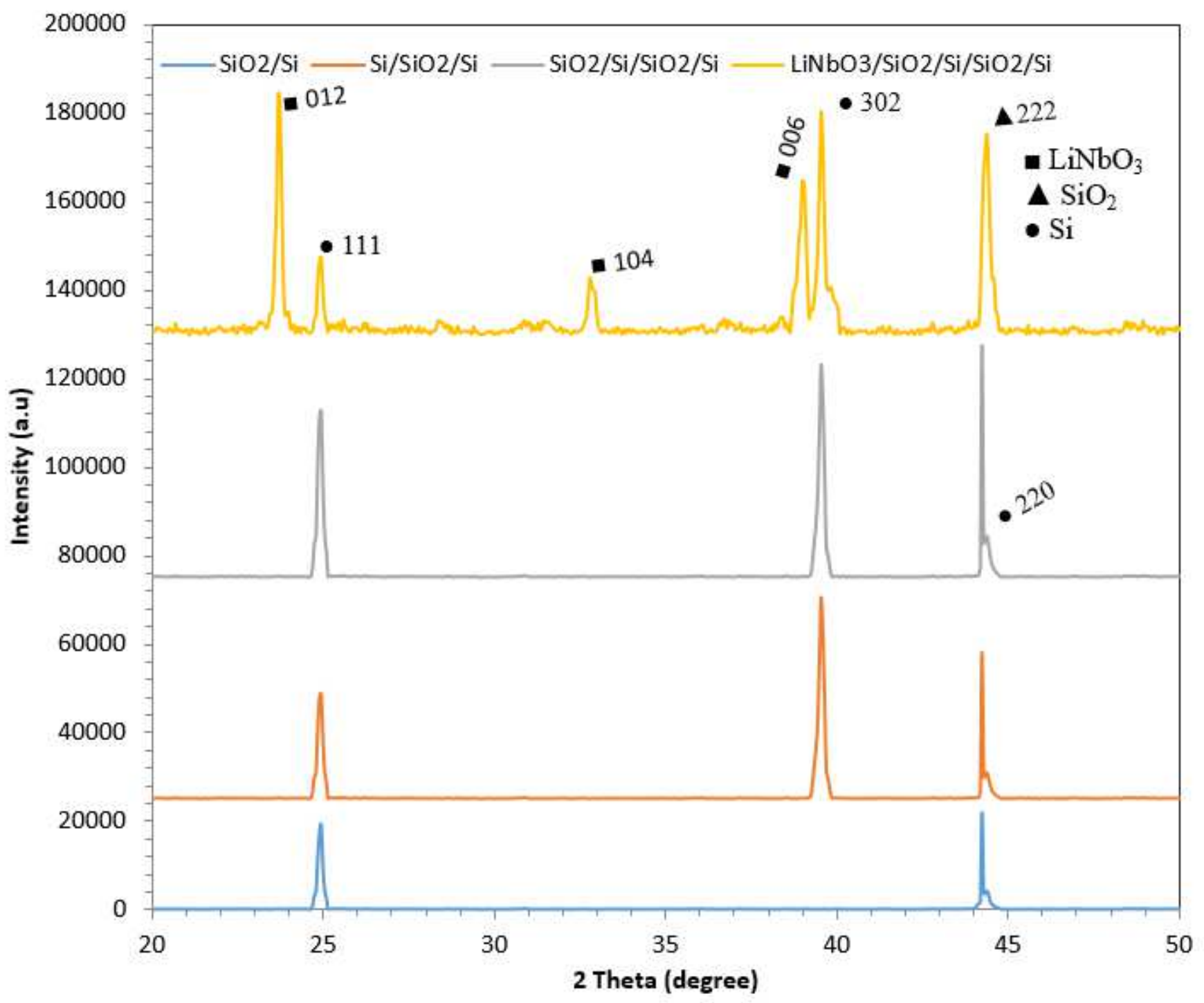

Figure 2

XRD patterns of the MZM nanostructure on Si substrates
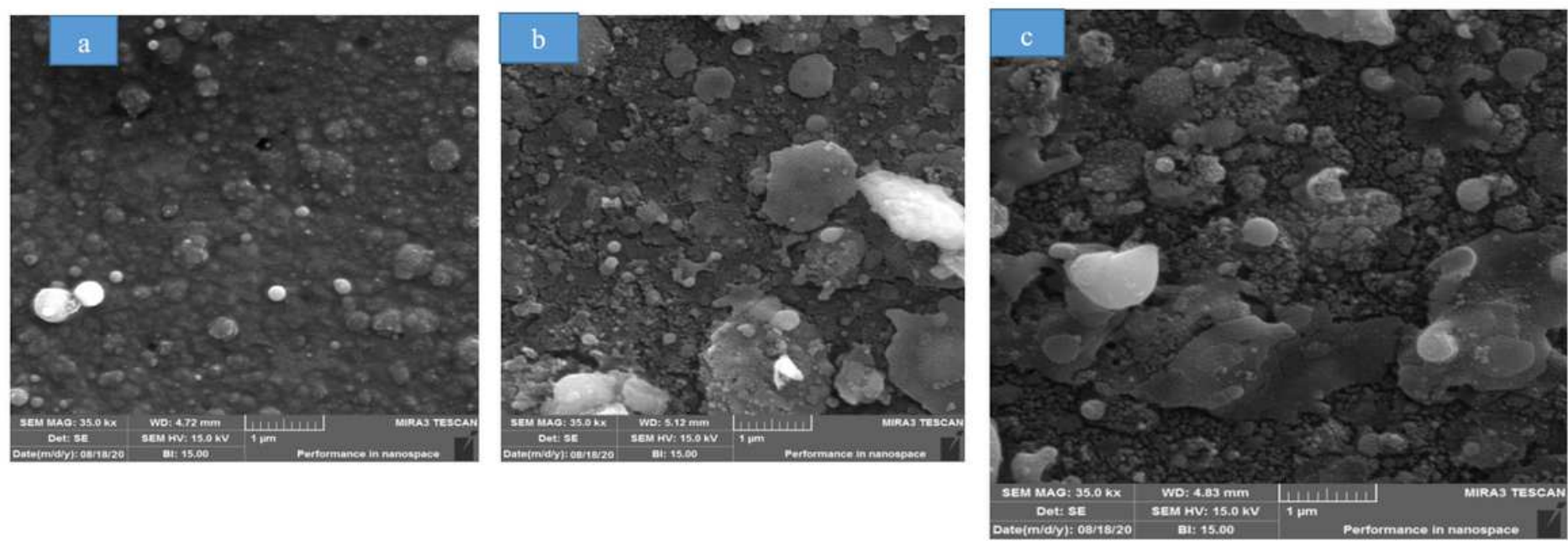


\section{Figure 3}

Surface morphology of hybrid MZM nanostructures prepared at different layer a) -SiO2/Si substrate, b) $\mathrm{Si}$ (waveguide)/SiO2/Si-substrate, and c) LN/ SiO2) Si(waveguide)/ SiO2 /Si substrate
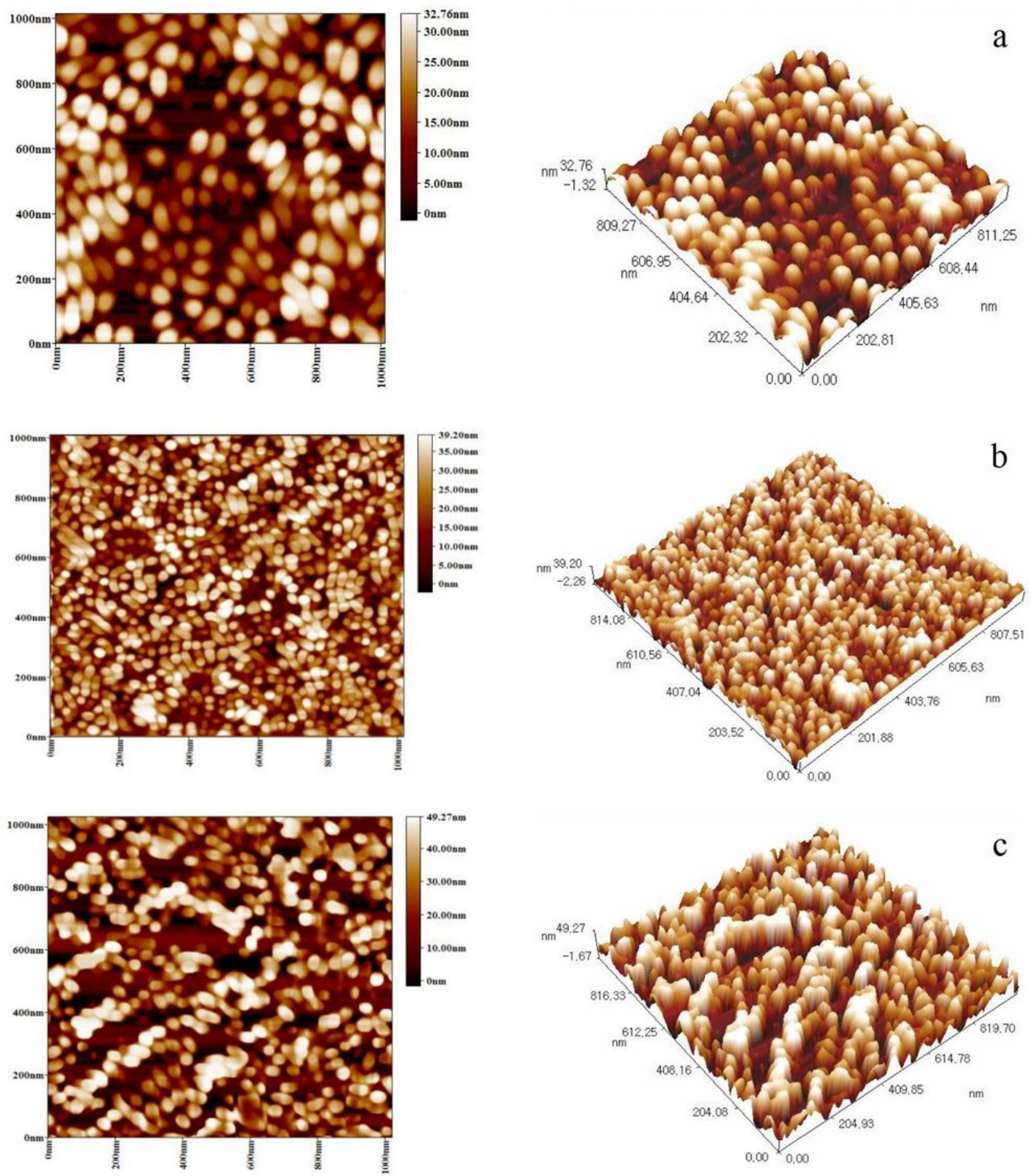

\section{Figure 4}

AFM images of nanostructured MZM a) (SiO2/Si), b) (SiO2/SiWG/SiO2/Si), and c) (LiNbO3/SiO2/SiWG/SiO2/Si) 


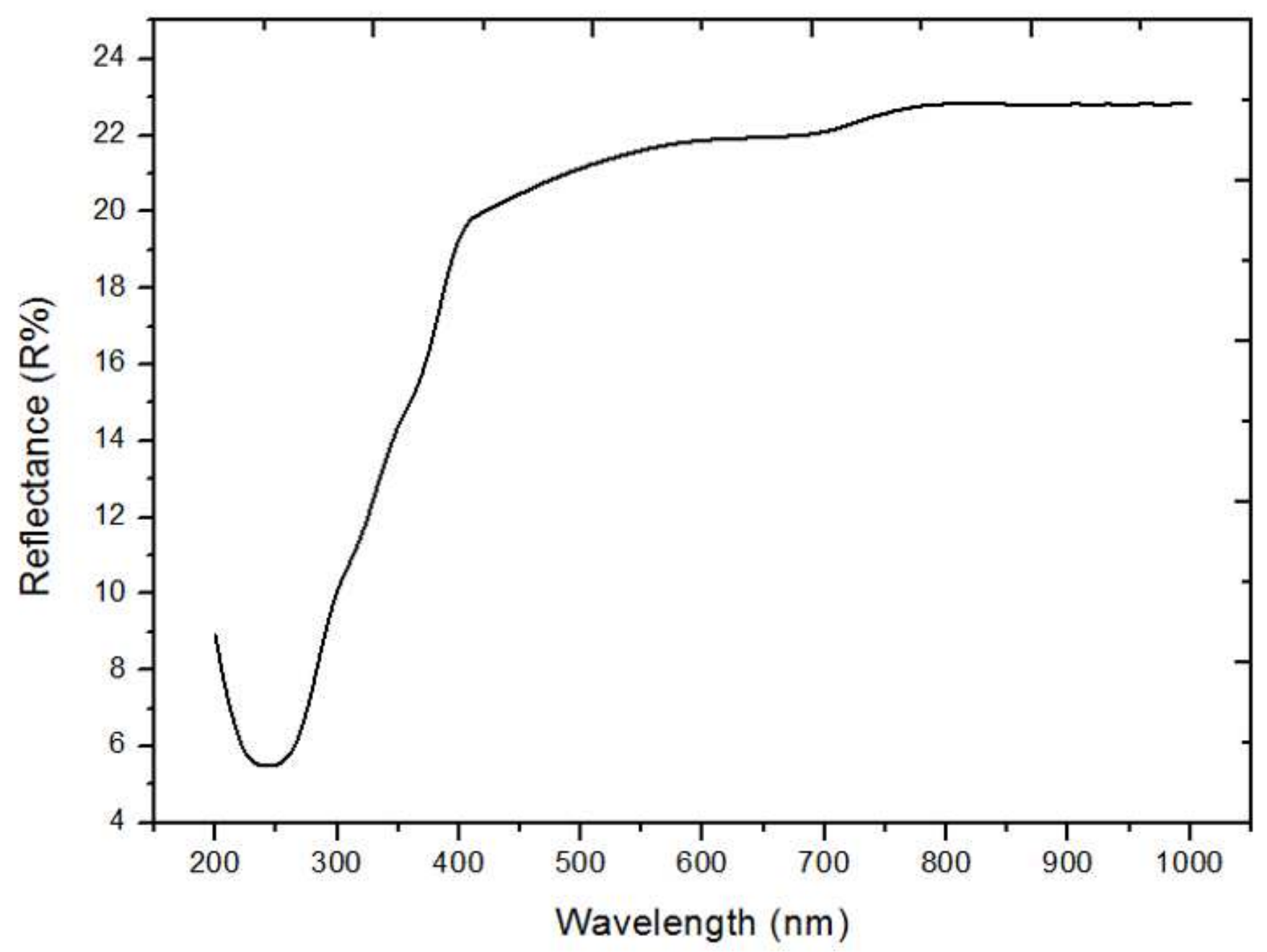

Figure 5

Reflectance diagram of the MZM prepared on Si- substrates. 


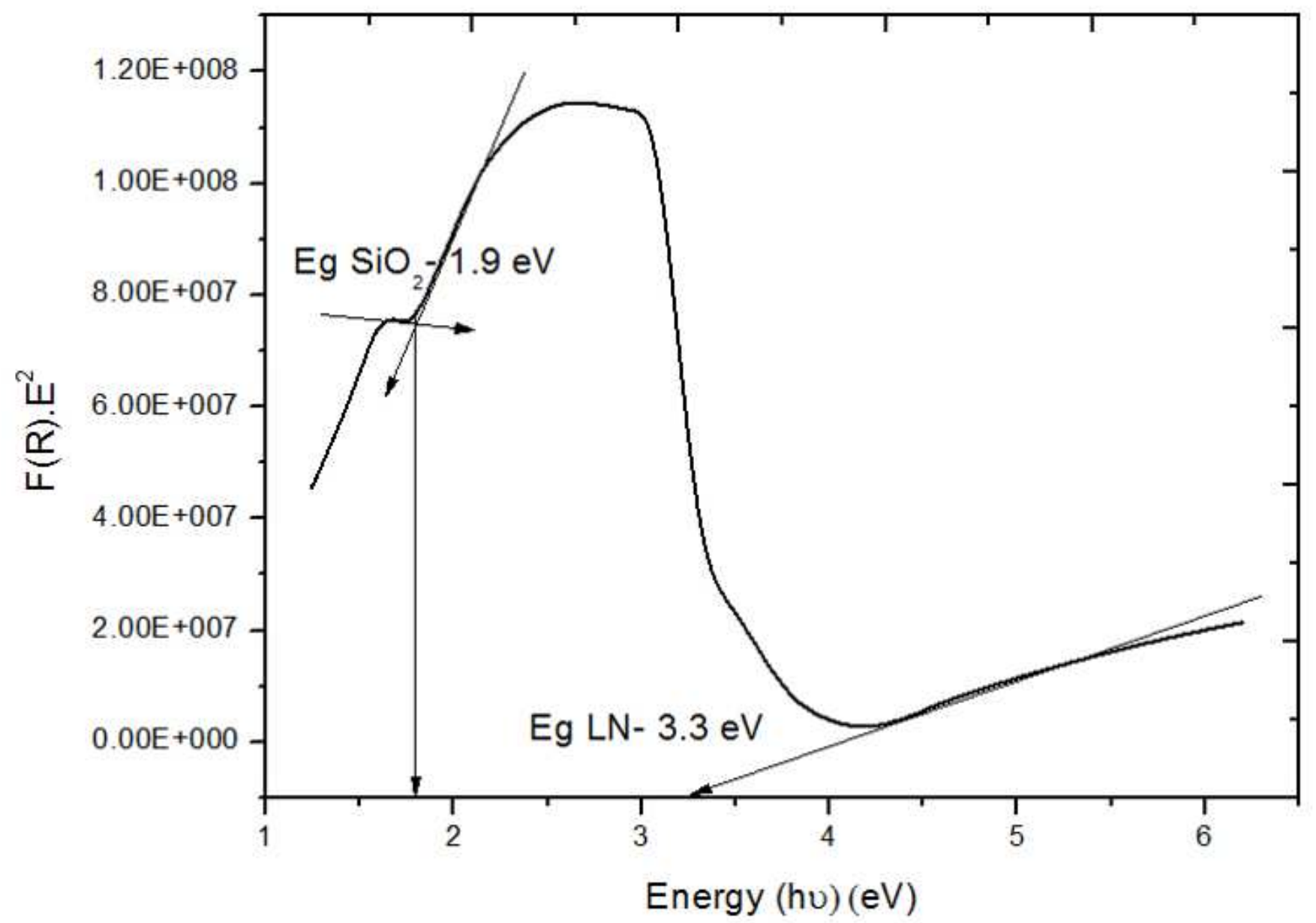

Figure 6

energy bandgap of MZM nanostructures 


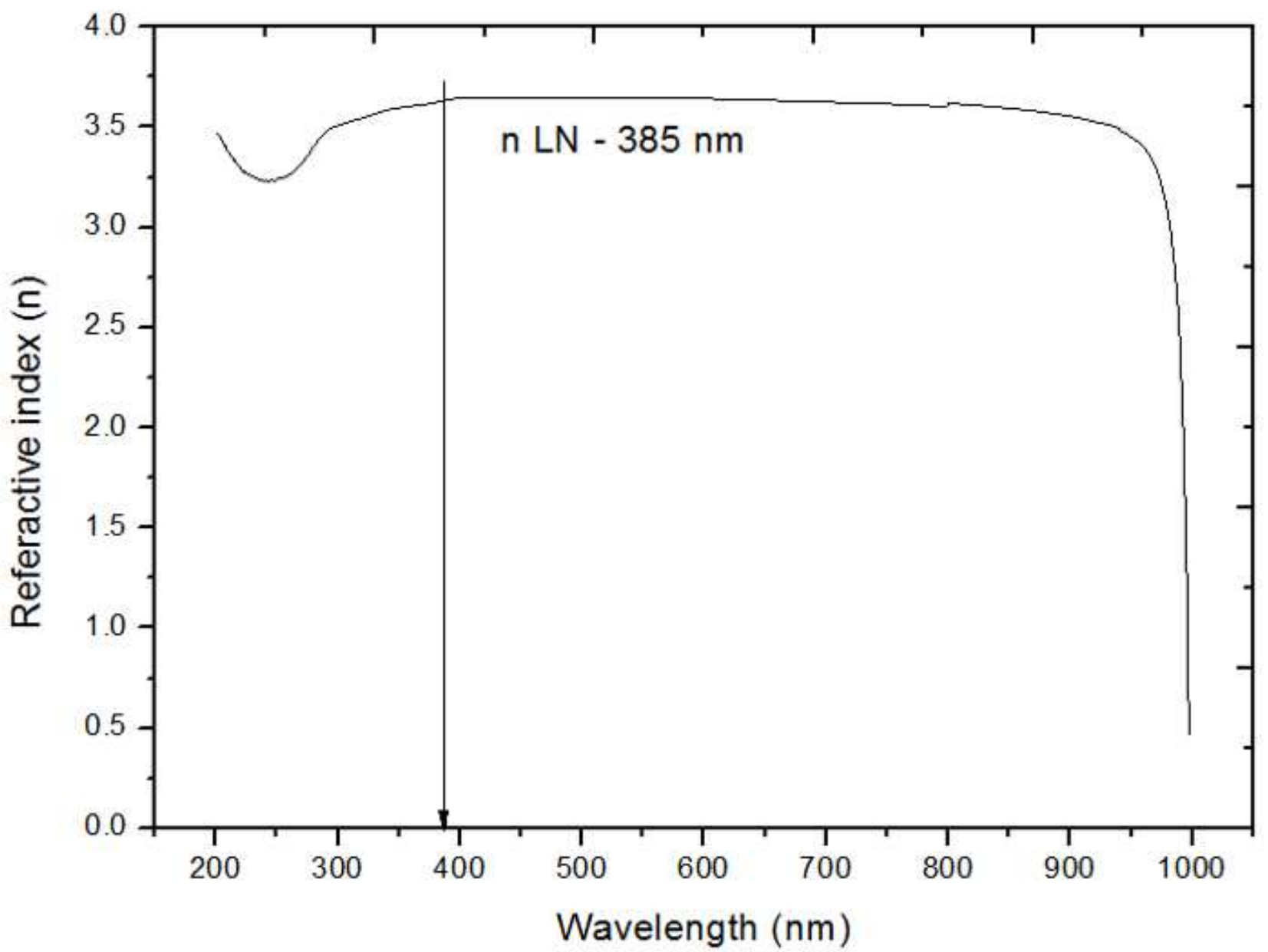

Figure 7

Refractive index of MZM nanostructure 


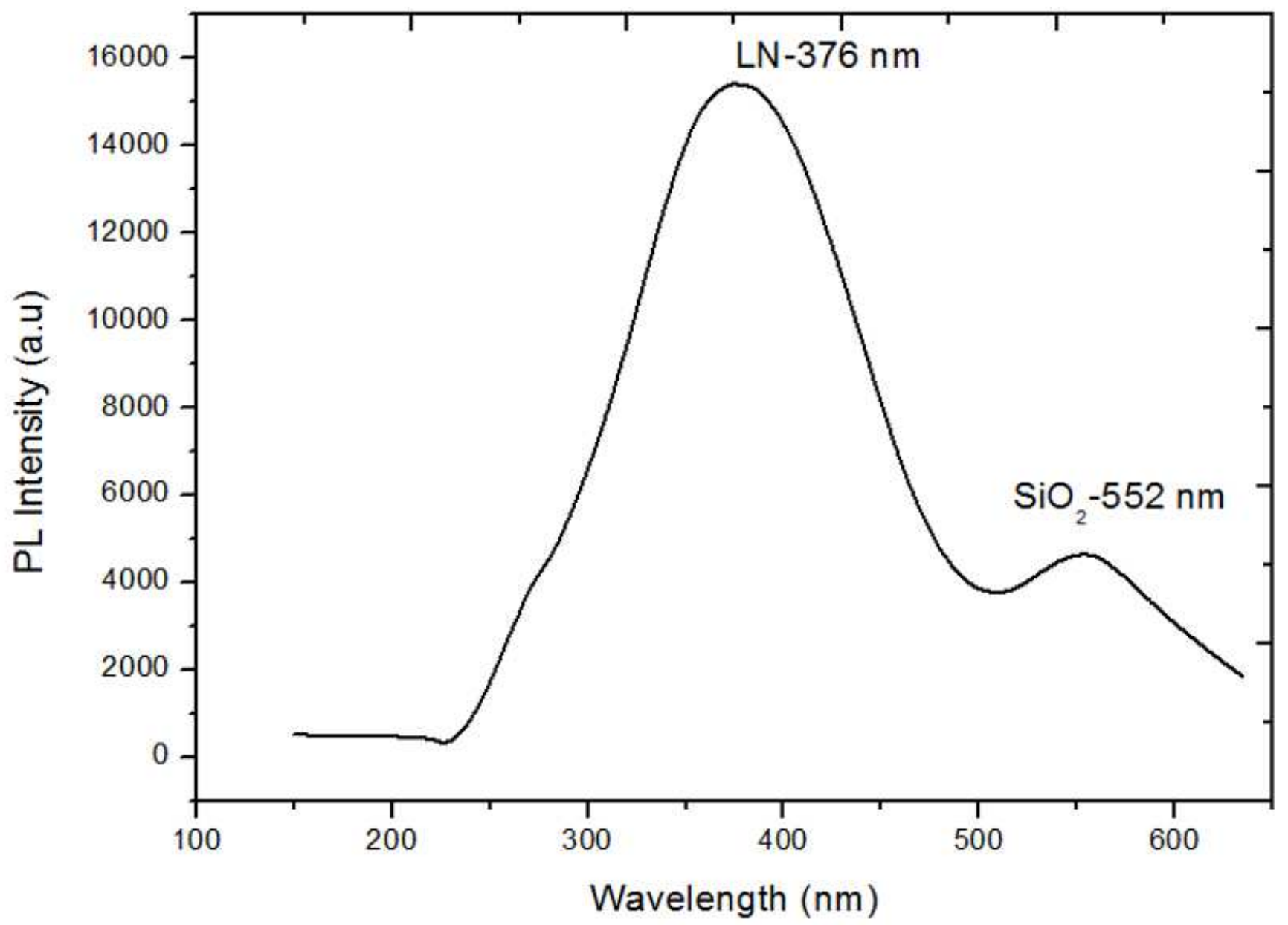

Figure 8

PL spectra diagram of hybrid MZM 